\title{
A Novel and Different Approach for the Synthesis of Quinoline Derivatives Starting Directly from Nitroarenes and Their Evaluation as Anti-Cancer Agents
}

\author{
Rizuana Sultana ${ }^{1}$, Ravinder Reddy Tippanna ${ }^{1}$ \\ ${ }^{1}$ Chemistry department, Mewar University, Rajasthan, India \\ Correspondence: Ravinder Reddy Tippanna, Chemistry department, Mewar University, India. \\ E-mail: ravinderclearsynth@gmail.com
}

Received: July 4, 2019 Accepted: January 28, 2020 Online Published: February 13, 2020

doi:10.5539/ijc.v12n1p99 URL: https://doi.org/10.5539/ijc.v12n1p99

\begin{abstract}
A series of new quinoline derivatives (6-phenyl-6H-chromeno, [4,3-b] quinoline) have been prepared by using 4-chloro-2-phenyl-2H-chromene-3-carbaldehyde and various substituted nitroarenes as starting materials in the presence of Tin (II) chloride dihydrate and ethanol. The conversion in this synthesis involves the following steps (i) reduction of nitroarenes to anilines, (ii) Coupling of the anilines, chromene aldehydes (iii) Cyclization of resulting species and (iv) dehydration of cyclic intermediates. Several new quinolones have been prepared. We screened eight compounds of this novel series (6a-r) in three different cancer cell lines (B16F10, MCF7 and A549). The screened compounds showed moderate anticancer activity on two of the studied cell lines with best $\mathrm{IC}_{50}$ values of compound $6 \mathrm{i}(6.10 \pm 1.23 \mu \mathrm{M})$ and $6 \mathrm{~m}$ $(8.21 \pm 2.31 \mu \mathrm{M})$ on MCF7 cells. The selected compounds $6 \mathrm{i}$ and $6 \mathrm{~m}$ led to morphological changes after treatment on MCF7 cell line. Interestingly, detailed studies suggested that the compounds $6 \mathrm{i}$ and $6 \mathrm{~m}$ induced apoptosis in MCF7 cells in an oxidative stress independent manner without causing necrosis. In addition, we found destabilization of mitochondrial membrane potential behind the observed anticancer activity. Our results clearly indicate the promising anticancer potential of this novel series. This method is operationally simple and works with a diverse range of substrates.
\end{abstract}

Keywords: Quinolines, Chromeno-3-carbaldehyde, apoptosis, Anti-cancer agents

\section{Introduction}

The use of privileged structures in drug discovery has proven to be an effective strategy, allowing the generation of innovative hits/leads and successful optimization processes, (Musiol et al, 2017) Chromene and Quinolines are recognized as a privileged structures and useful templates for the design of novel compounds with potential pharmacological interest (Fig. 1), (Fernanda et al, 2017, Fernanda et al, 2014) Undoubtedly, quinoline-based compounds have a remarkable impact on anticancer drugs. The quinoline moiety offers a simply accessible, well-understood scaffold for designing new drugs. It is also a very potent molecule with the druggability for structure optimization through established synthetic pathways. For these reasons, quinoline-core anticancer drugs have a strong position in modern medicinal chemistry. (Musiol et al, 2017)
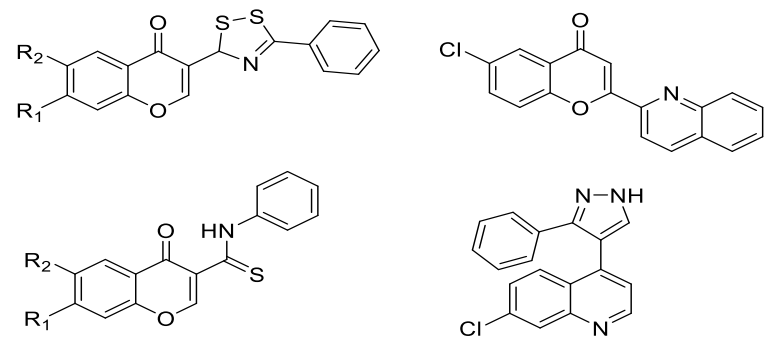

Figure 1. Chromene and Quinoline scaffolds emerged from the biological screening on cancer cell lines 
Particularly in the field of neurodegenerative, infectious and inflammatory as well as diabetes and cancer. (Peczynska-Czoch, 1999) Moreover, as drug repurposing is becoming an attractive drug discovery approach, recent studies of chromene based drugs are also reported. (Musiol et al, 2017) Quinolines and Chromenes are frequently found structural units in biologically potent natural products, (Michael 2005) in particular, alkaloids.

In addition, various quinoline derivatives exhibit a broad range of pharmacological properties such as anti-cancer, (Peczynska-Czoch, 1999), (Connie, 1995) anti-tuberculosis, (Singh, 2004) anti-hypertensive, (Leonard, 2004) anti-HIV, (Nevinsky, 1999) and anti-alzheimer activities. (Luque, 2001) Substituted quinolones function as antagonists for $5 \mathrm{HT}_{3}$, NK-3, endothelin and leukotriene receptors. (Pinto et al, 1995) They are also utilized as intermediates for the design of bio-potent molecules. (Cuny et al, 2000)

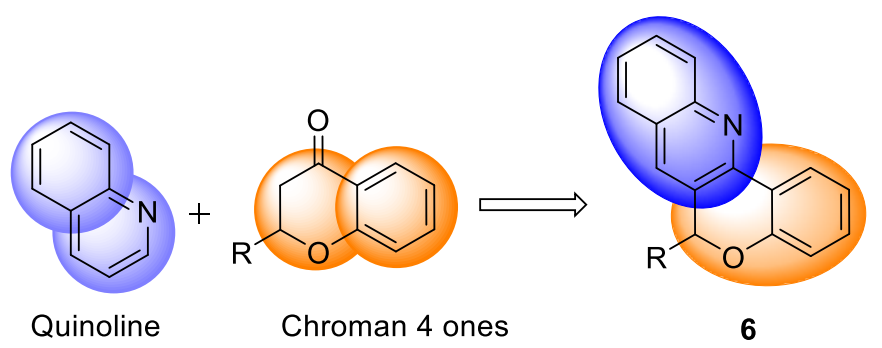

Figure 2. Combination of Chromene \& Quinolines hybrids as potential anticancer agents

\section{Results and Discussion}

The ability to create carbon-carbon carbon-nitrogen bonds is at the heart of organic synthesis, heterogeneous catalytic processes are particularly apt at creating such bonds, especially in reductive amination or relay sequences where more one bond is formed allowing for rapid assembly of complex structures. The present method has proved to be a particularly powerful tool for the intramolecular creation of carbon-carbon and carbon-nitrogen bonds by using $\mathrm{SnCl}_{2} \cdot \mathrm{H}_{2} \mathrm{O}$ and EtOH . We herein report a protocol for the construction of chromeno quinoline hybrid comprising Tin (II) Chloride dihydrate catalyzed reductive cyclization of nitroarenes and chromenes, nitroarenes reduction is useful in pharmaceutical industry because nitro-substituted product can be reduced by $\mathrm{SnCl}_{2} \cdot \mathrm{H}_{2} \mathrm{O}$ to yield aryl amine. It involves reduction of the nitro arenes to anilines (Liu et al, 2002) which in the proximal presence of Chromeno 3-aldehyde ( $\mathrm{Z}$ ) would undergo cyclization, and dehydration of the intermediates to furnish the desired product, in straightforward manner (Fig. 2).

In continuation of our work, we report the method by using starting material 4-Chloro-2-aryl-2H-3-chromene carbaldehyde 4 prepared from 2-phenyl chroman-4-one 3, through Vilsmeier-Haack reaction, (Subbarao et al, 1973) and compound 3 prepared by simple Mannich approach(Subbarao et al, 1973), (Baker et al, 1933) Scheme 1.

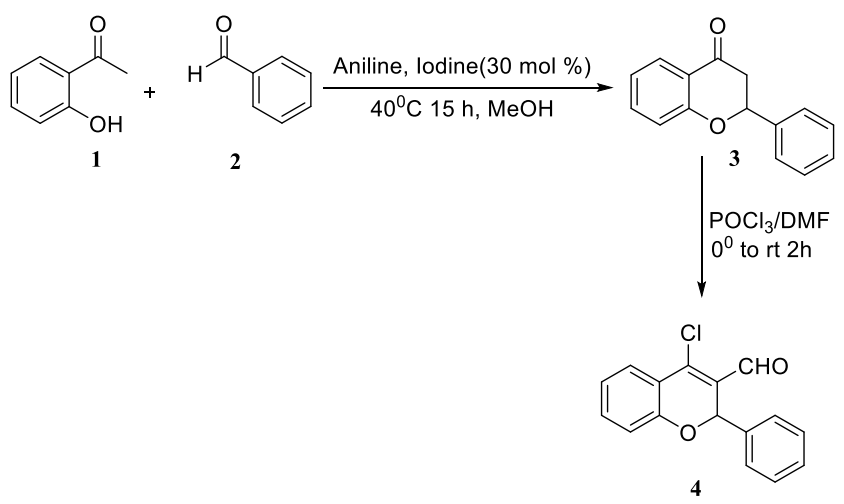

Scheme 1. Synthesis of starting material Chromene3-carbaldehyde using Mannich approach

The most common synthetic routes to prepare the flavanone $\mathbf{3}$ occurs via chalcone intermediate which involves the base catalyzed aldol condensation of 2-hydroxy acetophenones $\mathbf{1}$ with aromatic or conjugated aldehydes $\mathbf{2}$ in the presence of aniline and Iodine. The resulting chalcone $\mathbf{3}$ cyclized to produce flavanones via intramolecular $\mathrm{SN}^{2}$ reaction. (Ching-Fa et al, 2012) 
To explore the feasibility of this proposed strategy the reaction between known nitroarene $(\mathbf{5}, 1.2$ eq) and Chromeno 3-carbaldehyde (4, 1 eq) with commercially available $\mathrm{SnCl}_{2} \cdot 2 \mathrm{H}_{2} \mathrm{O}$ in EtOH at room temperature was performed (Table 1). Gratifyingly both starting materials were completely consumed in 8-12 h at room temperature and gave desired quinolone products (6) in 68-87\% yield (entry 1-18)

The nitro arenes contained electron withdrawing and electron donating groups. All example mentioned in Table 1 were performed easily when compared to earlier reports. The table also shows that the yields of substituted anilines are not affected by the nature or the position of the aromatic substituents on the corresponding nitrobenzene.

A plausible mechanism of the conversion is shown in Scheme 2. Initially, the nitroarenes $\mathbf{1}$ are reduced to anilines by $\mathrm{SnCl}_{2} \cdot 2 \mathrm{H}_{2} \mathrm{O}$ and these anilines react immediately with Chromene 3 aldehyde $\mathbf{3}$, producing the corresponding imines. The imine intermediate cyclized in the presence of light produces the quinoline derivatives $\mathbf{6}$. The conversion takes place spontaneously and no intermediate could be isolated.

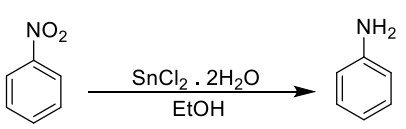

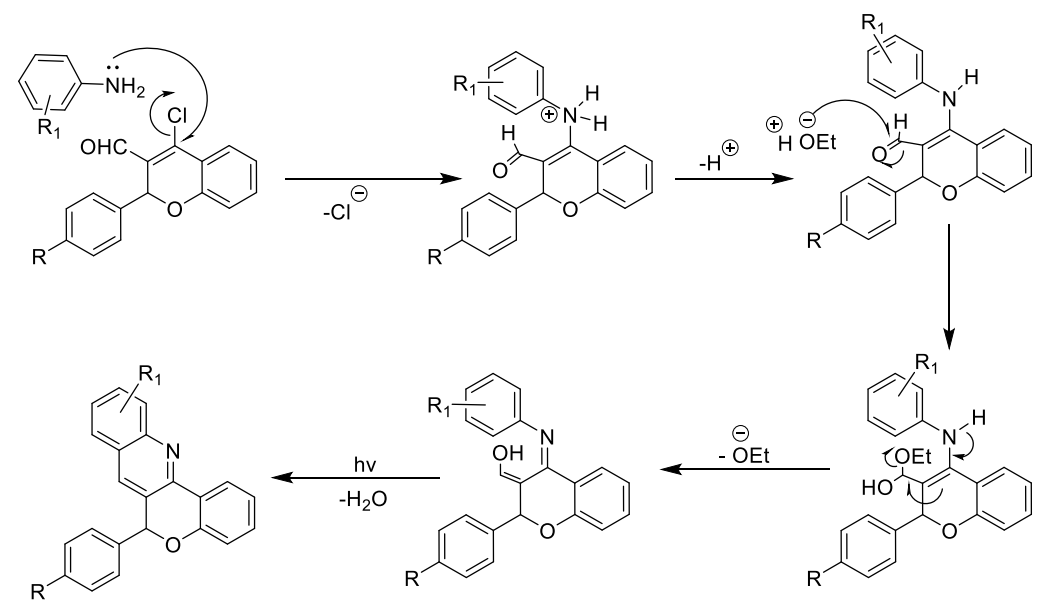

Scheme 2. The plausible mechanism of the formation of the 6-phenyl-6H-chromeno [4,3-b] quinoline 6(a-r) 
Table 1. Synthesis of the 6- phenyl- $6 H$-chromeno [4,3-b] quinoline 6 (a-r) from Chromeno 3 carbaldehyde

\begin{tabular}{|c|c|c|c|c|c|}
\hline Entry & $\mathbf{R}$ & $\mathbf{R}^{1}$ & $\begin{array}{l}\text { Product } \\
6\end{array}$ & $\begin{array}{l}\text { Time } \\
\text { (h) }\end{array}$ & Yield $^{\mathrm{c}}(\%)$ \\
\hline 1 & $\mathrm{H}$ & $\mathrm{H}$ & $\mathbf{a}$ & 8 & 85 \\
\hline 2 & $\mathrm{H}$ & $\begin{array}{l}\text { 3-OMe, } \\
\text { 4-OMe, 5-OMe }\end{array}$ & b & 2 & 68 \\
\hline 3 & $\mathrm{H}$ & 3-Me & $\mathbf{c}$ & 1 & 81 \\
\hline 4 & $4-\mathrm{Br}$ & $\mathrm{H}$ & d & 9 & 78 \\
\hline 5 & $\mathrm{OMe}$ & $3-\mathrm{F}$ & e & 10 & 84 \\
\hline 6 & $\mathrm{H}$ & 2-Me, 3-Me & f & 8 & 81 \\
\hline 7 & $\mathrm{OMe}$ & 3-Me & g & 12 & 77 \\
\hline 8 & $\mathrm{H}$ & $\begin{array}{l}\text { 2-Me, } 3-\mathrm{Br}, \\
5-\mathrm{Cl}\end{array}$ & $\mathbf{h}$ & 12 & 81 \\
\hline 9 & $3-\mathrm{Cl}$ & $4-\mathrm{OH}$ & $\mathbf{i}$ & 10 & 86 \\
\hline 10 & $\mathrm{H}$ & $4-\mathrm{F}$ & $\overline{\mathbf{j}}$ & 8 & 81 \\
\hline 11 & $\mathrm{H}$ & $4-\mathrm{Cl}$ & $\mathbf{k}$ & 10 & 83 \\
\hline 12 & $\mathrm{H}$ & $3-\mathrm{Br}$ & I & 12 & 85 \\
\hline 13 & $\mathrm{H}$ & $3-\mathrm{NO}_{2}$ & $\mathbf{m}$ & 10 & 82 \\
\hline 14 & $\mathrm{H}$ & 3-Me, 4-OMe & $\mathbf{n}$ & 12 & 87 \\
\hline 15 & $3-\mathrm{Br}$ & $4-\mathrm{OH}$ & o & 12 & 72 \\
\hline 16 & $\mathrm{H}$ & $\begin{array}{l}\text { 2-OMe, } \\
\text { 3-OMe, 4-OMe }\end{array}$ & $\mathbf{p}$ & 12 & 78 \\
\hline 17 & $3-\mathrm{Cl}$ & $\begin{array}{l}\text { 2-OMe, } \\
\text { 3-OMe, 4-OMe }\end{array}$ & $\mathbf{q}$ & 8 & 81 \\
\hline 18 & $3-\mathrm{Cl}$ & $\mathrm{H}$ & $\mathbf{r}$ & 12 & 85 \\
\hline
\end{tabular}

${ }^{a}$ Reagents and conditions: nitroarene $5(1.2 \mathrm{mmol})$, aldehyde $4(1.0 \mathrm{mmol}), \mathrm{SnCl}_{2} .2 \mathrm{H}_{2} \mathrm{O}(0.2 \mathrm{mmol})$, In EtOH (5 mL), reflux.

${ }^{\mathrm{b}}$ All the products were fully characterized by the usual spectroscopic techniques.

\subsection{In Vitro Cytotoxicity Assay}

In the present study with series compounds 6(a-r), three cancer cell lines (B16F10, A549 and MCF-7) were used. All the cell lines were procured from National Centre for Cell Sciences (NCCS), Pune, India. B16F10, and MCF-7 cells were maintained in DMEM (Sigma Aldrich, USA) media supplemented with 10\% fetal bovine serum (FBS, Gibco, USA), and Penicillin-Streptomycin (100 IU/mL each; Sigma Aldrich, USA), whereas A549 cells were maintained in RPMI-1640 (Sigma Aldrich, USA) media supplemented with FBS and antibiotic mix. The cytotoxicity assay was performed as per MTT (3-(4,5-dimethylthiazol-2-yl)-2, 5-diphenyl tetrazolium bromide) (Himedia, India) assay protocol as described previously.

Briefly, for cytotoxicity evaluation, 96 well plates (Eppendorf, Germany) were seeded with approximately 8000 cells/well and incubated overnight at $37^{\circ} \mathrm{C}$ and $5 \% \mathrm{CO}_{2}$ in a cell culture grade humidified incubator with HEPA filter for circulation of clean air (Eppendorf, Germany). The selected compounds 6(a-r) were incubated with cells for 48 hours at six different concentrations in triplicates $(3.12,6.25,12.5,25,50$, and $100 \mu \mathrm{M})$ prepared in respective plain media. After incubation, drug solutions were discarded and the cells were incubated with $100 \mu \mathrm{L}$ MTT solution/per well $(0.5 \mathrm{mg} / \mathrm{mL}$, prepared in plain media) for 4 hours. Thereafter, the formed formazan crystals were dissolved by adding $200 \mu \mathrm{L}$ dimethyl sulfoxide/well, and kept on orbital shaker for $20 \mathrm{~min}$. Thereafter, the absorbance was measured at $570 \mathrm{~nm}$ and results were quantified for the calculation of $\mathrm{IC}_{50}$ values. 


\subsection{Result Description}

To assess the cytotoxicity profile, we screened eight compounds of this novel series $\mathbf{6}(\mathbf{a}-\mathbf{r})$ in three different cancer cell lines (B16F10, MCF-7 and A549). The screened compounds showed moderate anticancer activity on two of the studied cell lines with $\mathrm{IC}_{50}$ values of compound $\mathbf{6 m} 33.97 \pm 3.27 \mu \mathrm{M}$ on B16F10 and 8.21 $\pm \mathbf{2 . 3 1} \mu \mathrm{M}$ on MCF7 cells, whereas A549 human lung carcinoma cells showed higher resistance with $\mathrm{IC}_{50}$ value of $45.85 \pm 5.14 \mu \mathrm{M}$. In addition, compound $\mathbf{6 b}$ and 6p also showed decent anticancer activity on two cells lines. Compound 6i produced anticancer cancer effect on MCF 7 cells with $\mathrm{IC}_{50}$ value of $\mathbf{6 . 1 0} \pm \mathbf{1 . 2 3} \mu \mathrm{M}$. Another compound $6 \mathrm{n}$ exhibited promising anticancer activity on B16F10 cells with $\mathrm{IC}_{50}$ value of $14.66 \pm 1.43 \mu \mathrm{M}$. Overall, the A549 lung carcinoma cell lines exhibited higher resistance as evident from the $\mathrm{IC}_{50}$ values of individual compounds as shown in table. The representative comparative percentage viability graph is shown in Figure 3.

Table 2. Cytotoxicity evaluation: $\mathrm{The} \mathrm{IC}_{50}$ values of different compound $6 \mathrm{a}-6 \mathrm{r}$ on three different cancer cell lines. Values are represented as mean \pm S.D. ( $\mathrm{n}=3$ of three independent experiments)

\begin{tabular}{|c|c|c|c|}
\hline $\begin{array}{l}\text { Compoun } \\
\text { d }\end{array}$ & $\begin{array}{l}\text { IC }_{50} \text { Value } \\
\text { on } \mathrm{B16F10} \\
\text { cells }(\mu \mathrm{M})\end{array}$ & $\begin{array}{l}\text { IC }_{50} \begin{array}{l}\text { Value } \\
\text { on } \\
\text { MCF-7 }\end{array} \\
\text { cells }(\mu \mathrm{M})\end{array}$ & $\begin{array}{l}\text { IC }_{50} \text { Value on } \\
\text { A549 Cells } \\
(\mu M)\end{array}$ \\
\hline $\mathbf{6 a}$ & $62.11 \pm 7.39$ & $31.46 \pm 3.83$ & $98.01 \pm 3.21$ \\
\hline $\mathbf{6 b}$ & $94.45 \pm 8.32$ & $17.10 \pm 2.84$ & $>100$ \\
\hline $6 c$ & $14.66 \pm 1.43$ & $31.15 \pm 1.83$ & $99.09 \pm 4.21$ \\
\hline 6d & $26.49 \pm 3.64$ & $21.20 \pm 1.63$ & $65.77 \pm 8.42$ \\
\hline $6 e$ & $45.85 \pm 6.14$ & $35.09 \pm 5.23$ & $88.87 \pm 5.21$ \\
\hline $6 \mathbf{6}$ & $62.11 \pm 7.39$ & $31.46 \pm 3.83$ & $98.01 \pm 3.21$ \\
\hline $6 \mathrm{~g}$ & $82.23 \pm 5.57$ & $70.95 \pm 8.37$ & $54.45 \pm 2.87$ \\
\hline 6h & $>100$ & $54.43 \pm 6.98$ & $89.12 \pm 9.32$ \\
\hline $6 \mathbf{i}$ & $18.45 \pm 3.25$ & $6.10 \pm 1.23$ & $54.67 \pm 5.14$ \\
\hline $\mathbf{6 j}$ & $26.49 \pm 3.64$ & $21.20 \pm 1.63$ & $65.77 \pm 8.42$ \\
\hline $6 k$ & $45.85 \pm 6.14$ & $35.09 \pm 5.23$ & $88.87 \pm 5.21$ \\
\hline 61 & $62.11 \pm 7.39$ & $31.46 \pm 3.83$ & $98.01 \pm 3.21$ \\
\hline $6 m$ & $33.97 \pm 3.27$ & $8.21 \pm 2.31$ & $45.85 \pm 5.14$ \\
\hline 6n & $14.66 \pm 1.43$ & $31.15 \pm 1.83$ & $99.09 \pm 4.21$ \\
\hline 60 & $33.97 \pm 3.27$ & $14.37 \pm 2.84$ & $78.78 \pm 5.31$ \\
\hline $6 p$ & $33.97 \pm 3.27$ & $14.37 \pm 2.84$ & $78.78 \pm 7.31$ \\
\hline 6q & $33.97 \pm 3.27$ & $14.37 \pm 2.84$ & $78.78 \pm 4.31$ \\
\hline 6r & $14.66 \pm 1.43$ & $31.15 \pm 1.83$ & $99.09 \pm 4.21$ \\
\hline
\end{tabular}

We examined the anti-proliferative activity of compounds to understand the concentration dependant effect of the selected compounds on cellular morphology of MCF-7, cells were treated with desired concentration of $6 \mathbf{i}$ and $\mathbf{6 m}(7.5,15$ and $30 \mu \mathrm{M})$ and cisplatin $(10 \mu \mathrm{M})$ as standard anticancer agent. (Kunal et al, 2014) Results of the morphological assessment based on phase contrast microscopy revealed profound changes in cellular morphology in a dose dependant manner (Fig 4). There was significant enhancement of chromatin condensation and apoptotic cells in a dose dependant manner as observed via EtBR/AO staining (Shivendra, 2011) (Fig 5). Interestingly, the death mechanism was found to be apoptosis as we did not observe any orange stained nucleus which is characteristic of cells dying via necrosis as EtBr can cross the nuclear membrane only if the membrane is leaky. In the present study, the cells were stained green mainly by acridine orange which is a vital dye and stains the nuclear material green. 


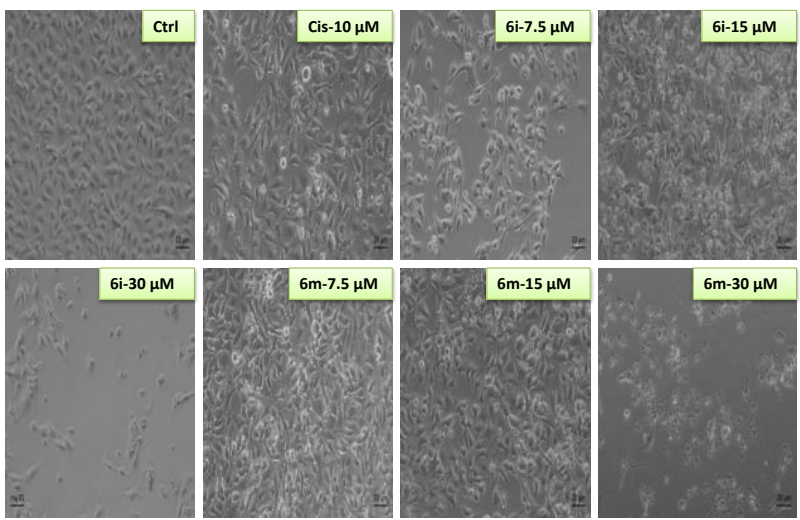

Figure 4. Effect of the selected compounds $6 \mathrm{i}$ and $6 \mathrm{~m}$ on morphological changes after treatment at concentrations of 7.5, 15 and $30 \mu \mathrm{M}$ for $24 \mathrm{~h}$ on MCF-7 cells as observed by phase-contrast microscopy, $10 \mu \mathrm{M}$ of cisplatin was used as standard compound
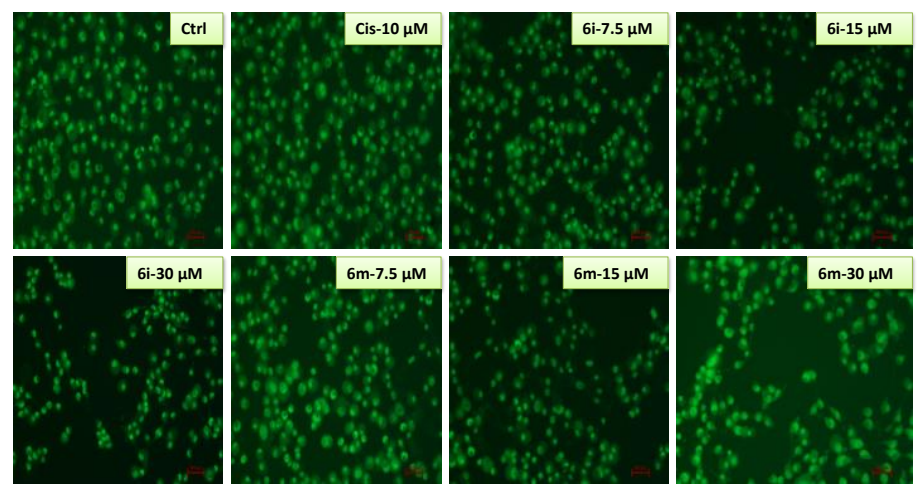

Figure 5. Effect of the selected compounds $6 \mathrm{i}$ and $6 \mathrm{~m}$ on nuclear morphology after treatment at concentrations of $7.5,15$ and $30 \mu \mathrm{M}$ for $24 \mathrm{~h}$ and staining with $\mathrm{AO} / \mathrm{EtBr}$ on MCF-7 cells as observed by fluorescent microscopy

After the morphological assessment, we investigated the dose dependant effect of the selected compounds on reactive oxygen species levels in MCF-7 cells. The cells were treated with selected compounds at dose dependant concentrations. Interestingly, we did not observe significant increase in the intracellular oxidative stress indicating that the cell death induced by the synthesized series compound is independent of oxidative stress (Fig 6).
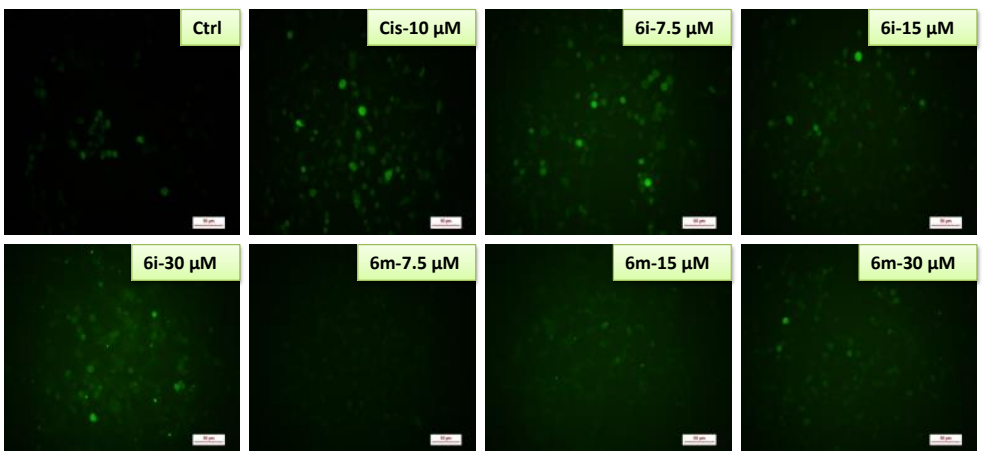

Figure 6. Effect of the selected compounds $6 \mathrm{i}$ and $6 \mathrm{~m}$ on intracellular reactive oxygen species levels after treatment at concentrations of 7.5, 15 and $30 \mu \mathrm{M}$ for $4 \mathrm{~h}$ and staining with DCFDA as observed by fluorescent microscopy

In addition, we estimated the integrity of mitochondrial membrane potential (MMP) via JC-1 staining. Strikingly, the compounds showed significant alteration of MMP in a dose dependant manner indicating the role of mitochondrial stress behind the observed anticancer effect (Kamal et al, 2015) (Fig. 7). 


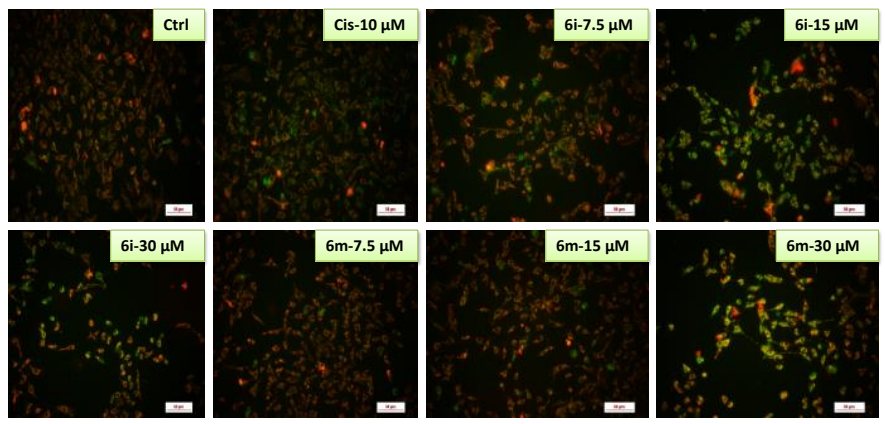

Figure 7. Effect on mitochondrial membrane potential of the selected compounds $6 \mathrm{i}$ and $6 \mathrm{~m}$ after treatment at concentrations of $7.5,15$ and $30 \mu \mathrm{M}$ for $24 \mathrm{~h}$ and staining with JC-1 as observed by fluorescent microscopy

\section{Conclusions}

In summary, a simple access for the synthesis of diverse novel quinolone derivatives (6-phenyl-6H-chromeno, [4, 3-b] quinolone) have been prepared by using 4-chloro-2-phenyl-2H-chromene-3-carbaldehyde and various substituted nitroarenes as starting materials in the presence of Tin chloride (II) dehydrate and ethanol. The conversion in this synthesis involves the following steps (i) reduction of nitroarenes to anilines, (ii) Coupling of the anilines, chromene aldehydes (iii) Cyclization of resulting species and (iv) dehydration of cyclic intermediates. Highly sterically demanding products, ambient reaction conditions, cost-effective catalytic system, good yields, operational simplicity, atom and step-economies are salient features of this strategy. A number of drug-like small molecules were prepared quickly and efficiently. We screened eighteen compounds of this novel series 6(a-r) in three different cancer cell lines (B16F10, MCF7 and A549). The selected compounds 6i and 6m led to morphological changes after treatment on MCF7. Further detailed studies such as acridine orange/ethidium Bromide (AO/EB), JC-1, DCFDA staining suggested that the compounds $6 \mathrm{i}$ and $6 \mathrm{~m}$ induced apoptosis in MCF7 cells in an oxidative stress independent manner. Moreover, the selected compounds caused disruption of mitochondrial membrane potential indicating impact on mitochondrial stability thus inducing apoptosis. Our results clearly suggest that these hybrids have the potential to be developed as apoptosis inducers against breast carcinoma.

\section{General reaction procedure for the synthesis of $6 \mathrm{a}-\mathbf{r}$}

To as stirred solution of nitro arene $(1.2 \mathrm{mmol})$ and appropriate chromene 3 - carbaldehyde $(1.0 \mathrm{mmol})$ in EtOH $(5 \mathrm{~mL})$, $\mathrm{SnCl}_{2} \cdot 2 \mathrm{H}_{2} \mathrm{O}$ catalyst $(0.2 \mathrm{mmol})$ were added and the reaction mixture was stirred at room temperature for $12 \mathrm{~h}$. The progress of reaction was monitored by TLC. The resulting solution was washed with sat. aq $\mathrm{NaHCO}_{3}(3 \mathrm{X} 5 \mathrm{~mL})$ and extracted with ethyl acetate $(3 \mathrm{X} 5 \mathrm{~mL})$. The organic layer was dried with sodium sulphate and concentrated under reduced pressure and further purified by column chromatography by using ethyl acetate/n-hexane to afford pure compounds 6a-r. All the synthesized compounds were characterized by ${ }^{1} \mathrm{H}$ NMR, ${ }^{13} \mathrm{C}$ NMR and ESI-MS.

\section{Acknowledgements}

Rizuana Sultana, Dr. Ravinder Tippanna, thankful to Mewar University for their constant encouragement.

\section{References}

Anzini, M., Cappelli, A., Vomero, S., Giorgi, G., Langer, T., Hamon, M., ... Pinto, J. C. (1995). Novel, Potent, and Selective 5-HT3 Receptor Antagonists Based on the Arylpiperazine Skeleton: Synthesis, Structure, Biological Activity, and Comparative Molecular Field Analysis Studies. J. Med. Chem., 38, 2692-2704. https://doi.org/10.1021/jm00014a021

Baker, W. (1933). Molecular rearrangement of some o-acyloxyacetophenones and the mechanism of the production of 3-acylchromones. Journal of Chemical Society, 51, 1381-1389. https://doi.org/10.1039/JR9330001381

Camps, P., Gomez, E., Munoz-Torrero, D., Badia, A., Vivas, N. M., Barril, X., ... Luque, F. J. (2001). Synthesis, in vitro pharmacology, and molecular modeling of syn-huprines as acetylcholinesterase inhibitors. J. Med. Chem., 44, 4733-4736. https://doi.org/10.1021/jm010949b

Gaspar, A., Matos, M. J., Garrido, J., Uriarte, E., \& Borges, F. (2014) Chromone: A Valid Scaffold in Medicinal Chemistry. Chem. Rev., 114, 4960-4992. https://doi.org/10.1021/cr400265z

Hahm, E. R., Moura, M. B., Kelley, E. E., Houten, B. V., Shiva, S., \& Singh, S. V. (2011). Withaferin A-Induced Apoptosis in Human Breast Cancer Cells Is Mediated by Reactive Oxygen Species. PLos One, 6, e23354. https://doi.org/10.1371/journal.pone.0023354 
Hoemann, M. Z., Kumaravel, G., Xie, R. L., Rossi, R. F., Meyer, S., Sidhu, A., \& Cuny, G. (2000). Potent In vitro methicillin-resistant Staphylococcus aureus activity of 2-(1H-indol-3-yl)quinoline derivatives. Bioorg. Med. Chem. Lett., 10, 2675-26178. https://doi.org/10.1016/S0960-894X(00)00542-4

Joana, R., Alexandra, G., Nuno, M., \& Fernanda, B. (2017). Chromone as a Privileged Scaffold in Drug Discovery: Recent Advances J. Med. Chem., 60(19), 7941-7957. https://doi.org/10.1021/acs.jmedchem.6b01720

Martyanov, I. V., Zakharova, O. D., Sottofattori, E., Pyshnyi, D. V., Yurchenko, E. Y., Babbi, P., ... Nevinsky, G. A. (1999). Interaction of oligonucleotides conjugated to substituted chromones and coumarins with HIV-1 reverse transcriptase. Antisense Nucleic Acid Drug Dev., 9, 473-480. https://doi.org/10.1089/oli.1.1999.9.473

Michael, J. P. (2005) Quinoline, quinazoline and acridonealkaloids. Nat. Prod. Rep., 22, 627-646. https://doi.org/10.1039/B413750G

Miller, D., Wang, S., Reid, J., Xie, W., Gauvin, B., Kelley, M., ... Faltynek, C. R. (1995). Approach to the discovery of novel, selective inhibitors of $\mathrm{p} 56^{\mathrm{lck}}$ tyrosine kinase: Identification of non-hydroxylated chromones as $\mathrm{p} 56^{\mathrm{lck}}$ inhibitors. Drug Dev. Res., 34, 344-352. https://doi.org/10.1002/ddr.430340406

Moorty, S. R., Sundaramurthy, V., \& Subba Rao, N. V. (1973). Synthesis of 4 chloro 3 formyl coumarins and of some coumarino $34 \mathrm{~d}$ isoxazoles and coumarino $34 \mathrm{~d}$ pyrazoles derived from them. Indian Journal of Chemistry, 11, 854-856.

Muruganantham, N., Sivakumar, R., Anbalagan, N., Gunasekaran, V., \& Leonard, J. T. (2004). Synthesis, anticonvulsant and antihypertensive activities of 8-substituted quinoline derivatives. Biol. Pharm. Bull., 27, 1683-1687. https://doi.org/10.1248/bpb.27.1683

Musiol, R. (2017). An overview of quinoline as a privileged scaffold in cancer drug discovery. Expert Opinion on Drug Discovery, 12, 583-597. https://doi.org/10.1080/17460441.2017.1319357

Osiadacz, J., Kaczmarek, L., Opolski, A., Wietrzyk, J., Marcinkowska, E., Biemacka, K., .. Peczynska-Czoch, W. (1999). Microbial conversion of methyl- and methoxy- substituted derivatives of $5 \mathrm{H}$-indolo[2,3-b]quinoline as a method of developing novel cytotoxic agents. Anticancer Res., 19, 3333.

Reddy, T. S., Kulhari, H., Reddy, V. G., Rao, A. V. S., Bansal, V., Kamal, A., \& Shukla, R. (2015). Synthesis and biological evaluation of pyrazolo-triazole hybrids as cytotoxic and apoptosis inducing agents. Org. Biomol. Chem., 13, 10136-10149. https://doi.org/10.1039/C5OB00842E

Sharma, S., Charanjit, K., Abhishek, B., Kunal, N., Manish, K. G., Saxena, A. K., \& Bedi, P. M.S. (2014). Chalcone based azacarboline analogues as novel antitubulin agents: Design, synthesis, biological evaluation and molecular modelling studies. Eur. J. Med. Chem., 85, 648-660. https://doi.org/10.1016/j.ejmech.2014.08.005

Vangapandu, S., Jain, M., Jain, R., Kaur, S., \& Singh, P. (2004). Ring-substituted quinolines as potential anti-tuberculosis agents. Bioorg. Med. Chem., 12, 2501-2508. https://doi.org/10.1016/j.bmc.2004.03.045

Veerababurao, K., Chunchi, L., Chun-Wei, K., Hulin, F., \& Ching-Fa, Y. (2012). Iodine catalyzed one-pot synthesis of flavanone and tetrahydropyrimidine derivatives via Mannich type reaction. Tetrahedron, 68, 1321-1329. https://doi.org/10.1016/j.tet.2011.11.022

Zhang, W., Jia, X., Yang, L., \& Liu, Z. L. (2002). Photosensitized Diels-Alder reactions of N-arylimines: synthesis of tetrahydroquinoline derivatives. Tetrahedron Letters, 43, 9433-9436.

https://doi.org/10.1016/S0040-4039(02)02328-6

\section{Copyrights}

Copyright for this article is retained by the author(s), with first publication rights granted to the journal.

This is an open-access article distributed under the terms and conditions of the Creative Commons Attribution license (http://creativecommons.org/licenses/by/4.0/). 